University of Rhode Island

DigitalCommons@URI

Cancer Prevention Research Center Faculty

Publications

Cancer Prevention Research Center

2010

\title{
A Network-Individual-Resource Model for HIV Prevention
}

Blair T. Johnson

Colleen A. Redding

University of Rhode Island, credding@uri.edu

Ralph J. DiClemente

Brian S. Mustanski

Brian Dodge

See next page for additional authors

Follow this and additional works at: https://digitalcommons.uri.edu/cprc_facpubs

This is a pre-publication author manuscript of the final, published article.

Terms of Use

All rights reserved under copyright.

\section{Citation/Publisher Attribution}

Johnson, B.T., Redding, C.A., DiClemente, R.J. et al. AIDS Behav (2010) 14(Suppl 2): 204. https://doi.org/ 10.1007/s10461-010-9803-z

Available at: https://doi.org/10.1007/s10461-010-9803-z

This Article is brought to you for free and open access by the Cancer Prevention Research Center at DigitalCommons@URI. It has been accepted for inclusion in Cancer Prevention Research Center Faculty Publications by an authorized administrator of DigitalCommons@URI. For more information, please contact digitalcommons-group@uri.edu. 


\section{Authors}

Blair T. Johnson, Colleen A. Redding, Ralph J. DiClemente, Brian S. Mustanski, Brian Dodge, Paschal Sheeran, Michelle R. Warren, Rick S. Zimmerman, William A. Fisher, Mark T. Conner, Michael P. Carey, Jeffrey D. Fisher, Ronald D. Stall, and Martin Fishbein 


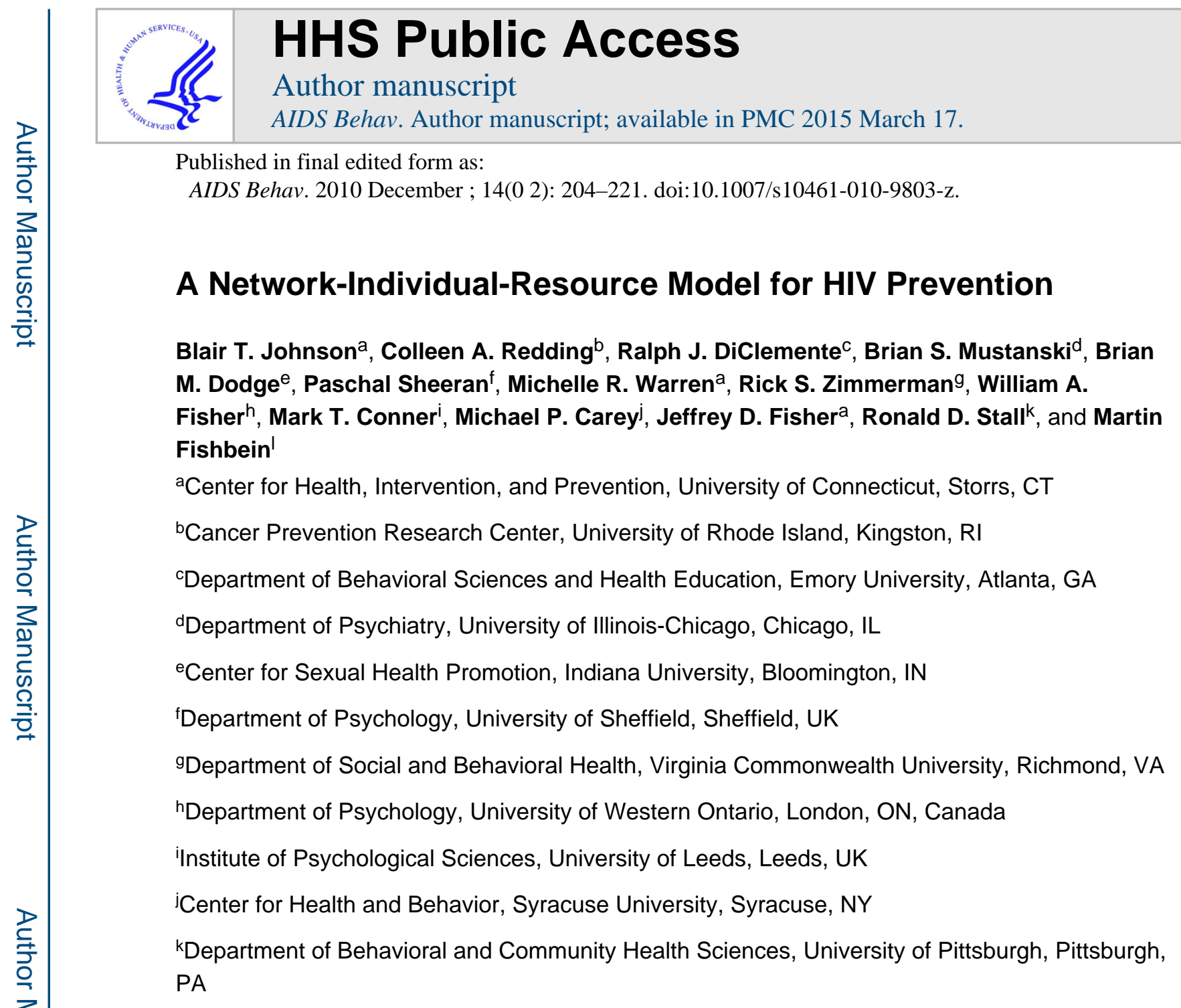

'Annenberg School for Communication, University of Pennsylvania, Philadelphia, PA, USA

\section{Abstract}

HIV is transmitted through dyadic exchanges of individuals linked in transitory or permanent networks of varying sizes. To optimize prevention efficacy, a complementary theoretical perspective that bridges key individual level elements with important network elements can be a foundation for developing and implementing HIV interventions with outcomes that are more sustainable over time and have greater dissemination potential. Toward that end, we introduce a Network-Individual-Resource (NIR) model for HIV prevention that recognizes how exchanges of resources between individuals and their networks underlies and sustains HIV-risk behaviors. Individual behavior change for HIV prevention, then, may be dependent on increasing the supportiveness of that individual's relevant networks for such change. Among other implications, an NIR model predicts that the success of prevention efforts depends on whether the prevention efforts (1) prompt behavior changes that can be sustained by the resources the individual or their networks possess; (2) meet individual and network needs and are consistent with the individual's

Address correspondence to Blair T. Johnson, Center for Health, Intervention, and Prevention, 2006 Hillside Rd., Unit 1248, University of Connecticut, Storrs, Connecticut 06269-1248, USA; (T) 860-486-2511; (F) 860-486-4876; blair.t.johnson@ @uconn.edu. 
current situation/developmental stage; (3) are trusted and valued; and (4) target high HIVprevalence networks.

\section{Keywords}

HIV prevention; health promotion; social structure; behavioral determinants; group behavior; resources

After 25 years, the HIV pandemic remains one of the most significant health threats that the world faces. Behavior change remains a necessary component in effective HIV prevention strategies; HIV transmission behaviors themselves are dependent on aggregated networks of individual, dyadic, and broader social forces. ${ }^{1,2}$ Unfortunately, past conceptual and empirical work has insufficiently integrated these elements and their reciprocal relations. ${ }^{3} \mathrm{~A}$ theoretical perspective that integrates both key individual and broader socio-cultural elements, offers the hope of better prevention outcomes that are resilient over time and that may be disseminated more broadly. Toward that end, this article introduces elements of a Network-Individual-Resource (NIR) model for HIV prevention that recognizes and addresses the substantial ties of individuals with their important social networks. Indeed, HIV is spread through individuals who are associated in one or more networks. Importantly, the NIR model maintains that risk for HIV, and the means to lower risk for its transmission, hinges on the interplay of resources between individuals and their networks. Individuals cope with their environments - remain safe, survive and thrive - by seeking and using physical and mental resources, which derive, in part, from their networks. Consequently, individuals act safely when they have safe mental and physical resources and they act unsafely when resources are insufficient. We commence by describing key components that underlie HIV-risk behavior: mental and physical needs and resources that individuals share with their networks. Then, we pose four postulates, describing how these key components interrelate and interact to foster risk, and, more interestingly, how they can be used to benefit prevention efforts. We identify several principles that exemplify these postulates and lead to strategies for prevention that offer synergy with extant HIV prevention interventions. We illustrate the importance of an NIR perspective with local and global factors associated with HIV prevalence, especially poverty, gender, sexual orientation, and race. We conclude with a discussion of existing challenges that HIV prevention models must surmount in order to halt the HIV epidemic. Despite the fact that little prior research has integrated elements across levels, the NIR model offers intuitive, commonsensical predictions that illustrate how these levels may operate through the mechanism of individuals with multiple networks that aggregate into larger units. We offer the current NIR model as a compass for future directions in research and a map for building synergy with effective individual-level programs to promote better HIV prevention outcomes.

\section{Central Variables}

\section{Mental resources}

Individuals possess mental resources that engender a degree of thriving over time. Past HIV prevention theory and research has identified key mental resources for acting safely as 
positive goal intentions to act in a safer fashion, aligned with positive attitudes toward such actions, allegiances with co-acting others that support these actions, and high perceived and actual control over such actions (Table I, top left cell). Some variables that are central and proximal in these models include goal intentions in relation to safer behaviors, behavioral skills, and perceived environmental constraints. Important other variables that usually have more distal influences on behavior include attitudes, social norms, self-efficacy or perceived behavioral control, and perceived risk. ${ }^{4-6}$ Various skills and developmental factors may also have important implications for HIV prevention, including maturity, ability to delay gratification for better rewards, ability to learn from mistakes, communication skills, negotiation skills, ability to trust, and relationship-level decision making. These factors are integrated in memory and are based on individuals' interactions with their tangible and social environments, constrained to some extent by each individual's genetic predispositions and other tangible resources (see following sub-section). ${ }^{7}$ Variability in these elements has consistently been shown to relate to behaviors that place individuals at risk for $\mathrm{HIV}^{8,9}$; similarly, when interventions have improved these elements, risk behaviors have declined. ${ }^{10-12}$

\section{Tangible resources}

No matter how well an individual's mental resources are aligned to support safe behavior, his or her access to appropriate tangible resources for safer behavior will limit the extent to which safer behavior occurs. As implied above, mental resources depend on the presence of sufficient tangible resources (Table I, middle column), which broadly speaking amount to material and energy stores that are affected by the actions of the individual and his or her networks in the past and present. Income and gifts are examples of positive tangible resources; thefts and assaults are negative examples. It must be recognized that such other tangible resources as air, water and sustenance are important resources to sustain biological life-indeed, without these basic tangible resources, mental resources also deteriorate.

Nonetheless, these resources are not relevant to an HIV prevention context unless they are unavailable in sufficient quantity or quality. Generally more relevant to the HIV risk context are such tangible resources as personal income, physical possessions, and physical health, and from a risk-reduction perspective, these include such specific items such as condoms or clean needles. Indeed, meta-analyses have documented that when interventions provide key needed tangible resources to their participants, risk behaviors decline. ${ }^{12-15}$ To the extent that mental and tangible resources are stable over time and may be shared and maintained with co-acting others (Table I), they are structural in nature.

Resources are valuable only to the extent that they satisfy pressing needs or can be maintained to satisfy future needs. The needs themselves may be biological or psychosocial and they may vary across times and situations. Although individuals belong to many networks and these units may have many different resources, the NIR model's focus on HIV prevention implies that those networks that potentially or actually enact behaviors that place individuals at risk for HIV are of most direct importance for prevention. For example, although a family's actions toward an adolescent child may help him or her cope and thrive generally, ultimately it is the adolescent's interaction with peers in social networks that may encourage HIV-risk behaviors such as unprotected sex or substance use, increasing the 
potential for HIV acquisition. Resources are exchanged in these interactions that reward the actors in the networks by helping to satisfy one or more needs. For example, a suckling infant gets nourishment and the interaction provides social rewards for both the mother and the child; yet, if the mother is HIV positive, breastfeeding may transmit HIV to the infant. The adolescent who joins a network of injection-drug-using peers may do so for social acceptance by this social network. It is easy to see how adolescents who are motivated to engage in a risk behavior - that is, have their mental resources aligned to be unsafe-will seek membership in social networks that have similar values and norms, thereby providing a supportive milieu that may continually reinforce promotion of risk behaviors. Prevention tactics must keep these dynamics central to be maximally effective. Of note, tangible resources that networks provide may be symbolic or in the structure of norms or laws that they enforce, and these resources may afford safer or riskier behavior.

Individuals not only seek and affiliate with networks that may provide resources to facilitate coping and avoid networks that thwart need fulfillment but also are involuntary members of other networks (e.g., physical families, ethnic groups, societies). Networks are an actual or potential resource for individuals that can have a positive or negative valence; that is, networks can promote either HIV risk or protective behaviors. Reciprocally, individuals are also a resource for networks, without which the network would not exist. Networks affect the availability and accessibility of resources and prescribe formal and informal norms guiding members' behavior. Consequently, even if an individual initially possesses mental resources that encourage safe behaviors, exposure and participation in a risky network may change these mental resources in an unsafe direction or constrain his or her actions so that safer behaviors, while preferred, may not be enacted in deference to social network normative influences.

\section{Networks}

A network can be defined as being composed of two or more individuals who share a characteristic in common, interacting either momentarily or permanently over time. From this perspective, networks range from dyads such as sexual and romantic partners, to families, peers, communities, or even societies. Networks exist at times when two or more individuals are allied to obtain and exchange resources to meet their needs; they are more stable to the extent that they meet the needs of their members and have sufficient resources to continue. ${ }^{16}$ Importantly, the networks to which each individual belongs change naturally across the lifespan depending on his or her changing needs and on the changing circumstances of networks that compete for that individual's attention, involvement (and other mental resources), and tangible resources. Networks with high stability, sufficient size, and resources formalize rules of behavior such that their members or other networks contribute resources, such as a degree of social capital, that are shared for the good of the network and its members (Table I). Networks often have less formal norms as well. To the extent that such practices or policies are endorsed or enforced by the network and its members, they may have important direct or indirect ramifications for health, including the spread of HIV. Table II lists four postulates, which create the formal structure of a NIR model, along with principles that derive from the postulates. We describe these in turn. 


\section{Postulate 1: Resources Enable Surviving and Thriving}

Individuals and their networks face stressors that demand the use and potential depletion of resources. Valued mental and tangible resources are under competition for use by other individuals and their networks. Competition might be very direct, such as with interpersonal or collective conflicts, shortages of condoms or clean needles, or with environmental factors such as extreme temperatures, food scarcity, or poverty. Competition may also take a less visible form, such as in the actions of microbes and pathogens (e.g., malaria, HPV), any of which can compromise immune function and increase an individual's susceptibility to HIV and other maladies. Indeed, acquiring HIV itself is a significant mental and physical stressor that may also dramatically impact the economic welfare of the individual and his or her important networks. ${ }^{17}$ Thus, the NIR model recognizes that altering behavior is more difficult to the extent that individuals and their networks face chronic and severe stressors and easier to the extent that they have environments and networks with resources that help them meet such challenges.

These aspects may be expressed as a first postulate of an NIR model (Table II), which is that individuals cope with their environments-remain safe, survive, and thrive-by seeking and using tangible and mental resources. Three broad implications follow from this postulate: (1) Inadequate resources impair coping in the face of stressors. Individuals act safely when they have safe mental and tangible resources and they are more likely to act unsafely when these are insufficient. Other factors equal, when tangible needs are minimally met, then mental resources guide behavior, meaning that individuals with mental resources supporting either risky or safe behavior are empowered to act accordingly, which is an empowerment principle of the NIR model. Thus, an individual who has sufficient tangible resources and whose mental resources support risky behavior will tend to engage in risky behaviors and the reverse is true for those whose resources support safe behavior; we provide caveats that moderate these tendencies below. (2) Inadequate resources hamper the efficacy of active, psychosocial educational HIV prevention efforts, which may be labeled a disparity principle. Importantly, those who lack basic means will have difficulty maintaining safer behavior because efforts to satisfy their tangible basic proximal needs may often far outweigh distal, probabilistic concerns about HIV infection. A homeless adolescent engaging in transactional survival sex provides one example. Finally (3), an active prevention principle also follows: Prevention efforts that also ameliorate existing mental or tangible resource deficits will succeed better than those that ignore such deficits. In the short term, to the extent that these efforts meet the recipients' needs and those of their networks, safer behavior should result. In parallel, prevention efforts should have greater initial success for recipients who have the most acute needs. In the long term, in contrast, behavior change is likely to diminish for these same recipients who must seek alternative means of meeting their needs to the extent that the intervention-provided resources are no longer available or not sustainable (i.e., the disparity principle). An implication is that sustainable prevention effects should be the most difficult for the most economically disadvantaged populations. For such populations, economic or other interventions are also indicated (e.g., microcredit interventions, job training, education, anti-stigma campaigns), to address unmet needs and enable long-term behavior maintenance. 
Documenting the importance of resources are worldwide disparities in health and sexual health. Sub-Saharan Africa, for example, is one of the poorest regions in the world, with extremely limited health care, and includes at least two-thirds of the world's HIV cases; ${ }^{18,19}$ morbidity and mortality have been dramatic ${ }^{20}$ and threaten the political and economic future of many African nations. ${ }^{19}$ Worldwide, disenfranchised individuals are disproportionately at risk for HIV and are most likely to die from AIDS. Poverty has many cofactors that have exacerbated the spread of HIV, such as lack of education, limited access to care, poor maternal healthcare, racism, stigma, discrimination, transactional sex, gender inequity, and substance abuse. ${ }^{18,19,21-26}$ In addition, migration and war have interacted to worsen an already severe situation and increase populations' vulnerability to many diseases, including HIV/AIDS. ${ }^{27,28}$ Underlying these problems is a weakening of community (network) infrastructures that provide education and health resources and that exacerbate the effects of poverty. If anything, disparities that were present at the start of the HIV epidemic 25 years ago have grown larger as a result of HIV, which has appeared to "exploit or amplify existing social and economic disparities in many parts of the world." 29

\section{Postulate 2: Resources that Satisfy Pressing Needs Are Most Valued}

A second postulate of an NIR model is that individuals and networks value most those resources that satisfy their most pressing needs, whether they are tangible or mental. This postulate recognizes that individuals may value social and sexual interactions with others in their networks for their intrinsic hedonic value (a mental resource) rather than any tangible possession that is retained for an indefinite amount of time; of course, they may also value them for the tangible resources they provide. The value of particular tangible and mental resources hinges on each individual's present or projected biological and psychosocial needs at a particular time and situation. Individuals' needs vary widely across the lifespan: Prevention needs for neonates and children are dramatically different from emerging adults. Opioid addicts' needs are chronically aligned to seek another hit more than to seek sustenance; hunger may overwhelm long-term safety considerations and leave one vulnerable to enacting HIV risk behaviors that promise sustenance. Thus, the need for a particular resource (e.g., sustenance, belonging) at a given point in time may be stronger than the need for personal safety. A situational-developmental prevention principle follows: Optimal prevention efforts must match the situation and the developmental stage of the individual. Research on tailoring of message content is to some extent consistent with this principle. ${ }^{30}$ For example, provision of behavioral skills appears to have more influence in younger as opposed to older groups. ${ }^{7}$ Similarly, behavioral interventions to reduce risky sexual practices have been found to reduce the numbers of partners for adolescent African Americans but not for adult African Americans; members of younger networks may be more receptive to change. ${ }^{31}$ Such findings highlight important cultural differences attendant to different networks.

\section{Postulate 3: Networks are Actual or Potential Resources for Individuals}

Although an NIR model is consistent with extant theories' perspectives that individuals' mental and tangible resources are proximal determinants of HIV-related behavior, ${ }^{32}$ it recognizes that its two first general postulates must be considered in relation to important 
networks. That is, possession and use of tangible resources depends not only on individual mental resources (such as skills to maintain and use tangible resources safely) but also on important networks that affect the individual. Together, individuals and their networks generate and change situations that affect their ability to cope with challenges to surviving and thriving (Postulate 1); these changes create structural realities within which individuals interact. Consistent with these facts, a third postulate of an NIR model is that networks are an actual or potential negative or positive resource for individuals who are, in turn, also a resource for their networks. Individuals not only seek and affiliate with networks such as romantic partnerships, and peer groups that may provide resources to facilitate coping; but avoid networks that thwart need fulfillment or might actually impede coping. Individuals are also involuntary members of other networks (e.g., families, castes, races, societies) that may affect the availability of resources and therefore the satisfaction of needs. ${ }^{33}$ These relationships are reciprocal, with networks providing resources to the individual and vice versa. Whereas networks provide or withhold important resources, satisfying or thwarting one or more needs of the individual, they also establish formal or informal norms that guide their members' behavior and provide both formal and informal sanctions, designed to reinforce network prescribed norms.

Networks can have varied impacts on particular individuals or on other networks, and these impacts can appear either directly or indirectly. Social support in the form of many friends is known to improve immune function, ${ }^{34}$ societies that offer better medical care and higher financial resources tend to have lower incidence of HIV and other disease, ${ }^{35,36}$ and romantic couples who have high relationship quality are less likely to seek covert extradyadic sexual partners. ${ }^{37,38}$ These examples highlight how networks can reduce risk or improve coping through provision of appropriate resources. Consistent also with the first postulate are negative effects of networks: For example, drug-using networks can promote risky injection practices, ${ }^{39}$ networks of smokers maintain smoking, ${ }^{40,41}$ and gang networks promote gun violence and risky sex. ${ }^{42}$ In turn, individuals are important to networks to the extent that the individuals' participation in the network provides resources necessary for the network's existence, including mental resources such as training in skills, modeling, leadership, followership, or tangible resources such as provision of skills toward some aim, sustenance, or some other valued property. Individuals may wish to join a certain voluntary network because of its resource potential and therefore behave in a fashion that maximizes their chance of joining it, and networks may wish to recruit certain individuals to maximize the resources the network has and act in such a way as to recruit them. Networks also compete for new members and to some extent constrain or enable the involvement of their members in network activities through injunctive and descriptive norms or more direct strategies. ${ }^{43}$ Networks may also work to exclude individuals from membership, which may marginalize excluded individuals and prevent them from accessing network resources. ${ }^{44}$ In the most extreme case, war, networks may kill members of opposing networks. Of course, individuals belong to multiple networks that may differ in terms of norms, goals, resources, and reinforcements. Several implications follow from the third postulate, including a central role for trust, the realization that active intervention efforts should themselves be considered networking phenomena, and that greater effectiveness will result when involving members 
of the targeted network in the development and implementation of the HIV intervention activities themselves. We consider each of these implications in turn.

\section{A central role for trust}

Trust in networks accrues to the extent that the networks facilitate coping in relation to their members' inputs and resources, which supports the network's continued existence. Networks whose members act in defiance of safe health norms provide ample evidence that network trust and acceptance play extremely important roles in health behavior. Gays and lesbians, for example, have for generations felt disenfranchised from mainstream U.S. society, whose states' laws have only begun to permit same-sex marriages. ${ }^{45}$ Networks that treat members poorly signal low acceptance to the affected members, who respond by strengthening ties with other networks that are more instrumental and trusted. In the ultimate form, the "establishment" may become an enemy whose guidelines and mandates must be defied or mistrusted to support alternative networks. For example, gay men receive mixed messages that their relationships are of lesser value or meaningless, while simultaneously being told that safer sex should occur in the context of a meaningful and committed relationship. In the U.S., HIV prevalence remains highest among MSM, and recent epidemiological trends show increasing rates of infection, particularly among young MSM of color. ${ }^{46}$ Among MSM, recent estimates are that $68 \%$ of HIV transmissions result from main sex partners. ${ }^{47}$ One study of mixed-serostatus MSM couples reported that $71 \%$ had extradyadic sex, ${ }^{48}$ often occurring within the context of an explicit agreement to remain open to other partners. ${ }^{49}$ Such networks are, in turn, of key public health significance and present an important target for prevention efforts.

An NIR perspective aims to work with or enhance the safe resources a network possesses in efforts to reduce its risk of acquiring or spreading HIV. Importantly, prevention efforts should succeed better to the extent that participants trust the providers and participation is voluntary, especially when other resources are sufficiently supportive, which is the benevolence principle of an NIR model. The implication is that members of a targeted network should be recruited to assist in the development and implementation of HIV interventions. Perhaps best exemplifying use of this principle is the MPowerment Project, ${ }^{50}$ which endeavors to build strong, supportive communities of young gay and bisexual men who nurture and protect each other, especially by promoting HIV prevention; controlled trials have shown substantial reductions of high risk sex patterns. ${ }^{51,52}$ Similarly, the emerging trend in Community-based Participatory Research (CBPR) signals that to be sustainable, the target community (or the network, in NIR parlance) must be an active player in developing interventions and implementing these interventions for members of their network.

The NIR inverse, the malevolence principle, is that prevention efforts will fail when participants do not trust providers, participation is involuntary, or when resources are unsafe. Some examples here include: "Just say no" restrictions for U.S.-publicly-funded interventions and abstinence-only sex education may well have increased rather than decreased rates of STIs and pregnancy in adolescents ${ }^{53}$ because the approach failed to recognize the basic needs of adolescents within their networks. South African president 
Thabo Mbeki denied that AIDS was caused by HIV and supported a health minister who implemented policy on the basis that life-saving antiretrovirals are toxic; these actions might have dramatically increased the incidence of HIV in this country. ${ }^{54}$ When a leader denies the basic facts of HIV/AIDS and undercuts the gravity of acquiring the disease, his/her followers are left with little reason to practice safer behaviors. In contrast, Ugandan leadership quickly reacted at the outset of the HIV epidemic and implemented a comprehensive national strategy for HIV prevention, including promotion of the $\mathrm{ABC}$

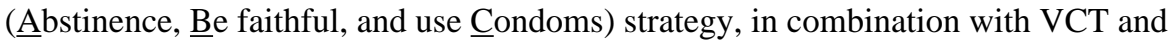
prevention of mother-to-child transmission. These actions led to a marked reduction in both HIV-associated behaviors and HIV prevalence. ${ }^{55}$

Also germane to the central role of trust is stigma in various forms, which signals to those who possess one or more stigmas that they are not accepted — and thus are not trusted — by those without the stigma. For example, many individuals continue to face stigma on the basis of their sexual orientation (i.e., homophobia, heterosexism, etc.), which can take the form of individual (e.g. family rejection, hate crimes) or institutional discrimination (e.g., laws criminalizing gay sex; laws against same-sex marriage), and can even become internalized by group members themselves. ${ }^{44,56,57}$ This stigma has negative consequences including discouraging long-term partnerships and reducing the stability of partnerships among MSM that may result in an increase in lifetime sex partners and greater likelihood of exposure to HIV. Experiencing stigma has also been found to have deleterious effects among gay, lesbian, bisexual, and transgender men and women, who often report higher numbers of mental health issues (i.e., depression, anxiety, suicides) in comparison to their heterosexual counterparts. ${ }^{58-62}$ Indeed, stigma may also be directly related to an individual's vulnerability to sexual risk taking and substance use. ${ }^{63}$ Gay men commonly fear being open about their sexual orientation due to possible adverse reactions (i.e., isolation, discrimination, and victimization) and such social adversity has been linked to a syndemic of health issues including HIV/AIDS. ${ }^{64,65}$ Overall, this multitude of issues creates an environment in which it is difficult to develop and deliver relevant and efficacious HIV prevention programs. ${ }^{66}$

Because HIV impacts some networks more than others and because some networks have higher resources (e.g., money, prestige, access to care), intergroup relations are a key consideration to HIV prevention. Stigma may apply to any network and its members and even be accepted by individuals (i.e., internalized stigma). Relevant to HIV, extreme negative stigma exists in many cultures for HIV-positive individuals, for people at highest risk for HIV seroconversion, and even for the high-risk activities themselves. The generally private nature of the behaviors that spread HIV means that they may persist despite opposing social norms from larger and more powerful networks. The stigma associated with group memberships and high-risk behaviors inhibits people from taking advantage of such resources as clinics, testing, disclosing their HIV serostatus, and enacting risk-reduction behaviors because of fear of losing social or material support, which may disrupt membership in important social networks. ${ }^{67}$ An NIR perspective would encourage such practical solutions as (1) anti-stigma campaigns that enhance affected individuals' ability to take such corrective actions as visiting STI clinics or VCT centers, disclosing their HIVpositive serostatus, taking ARVs, and feeding infants generic formula; or (2) when stigma is 
insurmountable in the short run, offering means of supporting affected individuals in ways that allows them to avoid stigmatization (e.g., by offering transportation to medical services at locations where they may remain anonymous).

An NIR perspective encourages understanding the ecology of a network and then attempting, directly and indirectly, to reduce its members' risk behaviors. Network-level interventions (Table I, bottom 4 rows) will be more successful to the extent that we understand the needs of such networks and how to mobilize them to promote safer health norms and to disseminate member-relevant information. Similar to the popular opinion leader (POL) approach, based on social diffusion theory, ${ }^{68}$ the NIR model predicts that prevention efforts should target the most influential members of the network as a strategy for disseminating safer health norms. Such leaders may be influential either because, as in the POL approach, they provide important social resources to the network (e.g., acceptance of other network members by a high-status source) or, perhaps even more importantly, because they provide other tangible resources. The POL approach is of particular relevance to the NIR model because it explicitly recognizes the potential of providing resources to members of a particular population that then diffuse through the network. The NIR model predicts that the success of such interventions is likely to be highly variable, hinging on the supportiveness of the resources of the individuals' networks for the desired behavior change. The implication is that HIV prevention interventionists should whenever possible evaluate and strengthen the supportiveness of network members for any proposed behavior changes. Many POL interventions may fail, for example, because the risk networks in question are too unstable over time; the label of "popular opinion leaders" has little meaning when a network is transitory or even exists to be transitory in order to facilitate unsafe sexual or drug behaviors in the first place. Interventions that successfully improve tangible or mental resources relevant to networks may have direct impacts on HIV-related behaviors or their effects may be mediated through a number of the key individual variables that have been well researched in this area. ${ }^{4-6}$

Interventions have already begun to harness the power of networks. For example, Stanton and colleagues built social networks into the delivery of their HIV prevention intervention by having students sign up for sessions with their friends; behavior changes were better sustained if delivered in friendship groups. ${ }^{69-71}$ Valente and colleagues randomly assigned classrooms to receive a substance abuse prevention intervention in which they were organized into groups with their friends or were organized into groups randomly. ${ }^{72}$

Differences between the two conditions were moderated by the level of risk of individuals in the groups: For individuals in groups with other relatively high-risk individuals, those in the groups comprised of friends had worse outcomes than those comprised of randomly assigned individuals; for individuals in groups with relatively low-risk individuals, those who received the intervention with their friends had better outcomes than those assigned randomly to groups. These results clearly suggest that better understanding of network characteristics and targeting interventions to various network types could indeed make a difference in improving outcomes.

Ultimately, a network's impact on an individual depends on the nature of the actions that the network takes in relation to the individual, consistent with the first postulate. As a passive 
prevention principle, networks with sufficient resources may enact changes that facilitate or hinder HIV prevention, regardless of the degree of trust held by the member in the network. Thus, even a mistrusted government might enact tangible changes or economic policies that facilitate the welfare of one or more networks in its system. A government might enact laws that support same-sex marriage, for example, thereby incentivizing long-term monogamy and decreasing the relative value of alternative, non-monogamous networks that have higher risk. Note that resource exchanges at work in long-term partnerships have clear economic ramifications, which is also consistent with the NIR model's benevolence principle. Thus, many structural changes may only be realized over a long period of time, perhaps generations in some cases.

\section{Behavioral interventions are networking}

An NIR perspective embraces the fact that active prevention efforts are networks themselves, and their success depends on strategies and resources for recruitment and retention ${ }^{73}$ and their ability to convey valued resources to their members. Thus, prevention networks recruit individuals to take part in their resource-providing services. In turn, it follows that the success of such efforts is limited not simply by their ability to recruit members, ${ }^{73}$ but also by (1) the degree of trust and value that individuals have in the HIV prevention efforts themselves, (2) the extent to which the prevention efforts provide needed resources for the participants' use, and (3) the extent to which the intervention content is consonant with the individual's most salient networks (Table I, right-most column). These considerations make it evident that the success of an intervention may hinge as much on the fact that it provides incentives (financial, social) as on its prevention content. These ideas imply that dissemination of demonstrated effective interventions across cultural settings or across levels of resource scarcity will need to be much more closely attuned not only to the fidelity of the intervention, but to the cultural and resource contexts in new settings.

The degree of influence any network has on an individual depends on the importance of that network to the individual and the nature of the power that the network may wield. A network's importance to an individual, in turn, depends on how much and how well it satisfies that person's needs, how much the individual identifies with the network, or how much legitimate or illegitimate power the network has in relation to the individual. ${ }^{74} \mathrm{It}$ follows that even well-designed interventions that address a network of superficial importance to an individual or one that is opposed by the individual will have minimal impact on that individual. Therefore, even well-designed interventions will have minimal long-term impact if the behavior changes entailed by the intervention face resistance from the network that the participant affiliates with most when he or she leaves the intervention. The implication is that HIV prevention efforts need to accommodate the culture of the important networks in any targeted community or they are likely to be less effective or fail altogether.

Consistent with an NIR perspective, women's risk for HIV varies worldwide and reflects factors that stem more from network, power, and structural factors than from individual risk behavior factors; this consideration illustrates the power asymmetries that can exist within members of networks and across networks. Although globally, women represent about 50\% 
of HIV infections, the gender disparity ranges from a high of $61 \%$ of adults with HIV/AIDS in sub-Saharan Africa ${ }^{66}$ to only $27 \%$ of adults with HIV/AIDS in the United States. ${ }^{75}$ Women's HIV risk varies dramatically in settings where women are impoverished ${ }^{21,76}$ and/or culturally disempowered, ${ }^{77}$ and where women outnumber men, ${ }^{78}$ all of which increase the likelihood of partner concurrency. Worldwide gender disparities, particularly in education, have greatly increased HIV risks for women. ${ }^{18,26}$ Extensive evidence reveals that sexual HIV transmission is 2 to 4 times more efficient from men to women than vice versa. ${ }^{79}$ Compounding these factors, women are too often targets of sexual violence, which increase HIV risks both directly and indirectly. ${ }^{80-84}$ For many women, the main risk of HIV infection comes not from their own risk behavior, but from that of a primary partner. ${ }^{23,80,85}$ Although some cultures accept multiple wives (co-wives) as normative, ${ }^{85}$ few studies have examined multiple-partner marriages. Thus, gender is an important risk factor for HIV worldwide and women's ability to protect themselves is limited by sociocultural and network factors, many of which are beyond their control. ${ }^{80,86,87}$ In contexts where violence against women is normative, well supported individual-level variables such as intentions to use condoms are less relevant because of lack of female power to enact or actualize these health promoting intentions. ${ }^{86}$ For example, the SISTA intervention ${ }^{88}$ for African American women includes both group-level empowerment and culturally relevant messages (and is being adapted for U.S. Latina and South African women as well ${ }^{89}$ ). Like the MPowerment Program, such interventions enhance linkages of individuals to an important collective. Worldwide gender disparities in HIV illustrate how important an NIR perspective is to the future development of contextually relevant prevention programs for women.

Unless interventions foster trust in the intervention efforts themselves, effectiveness is likely to remain low. African Americans, for example, often mistrust health care providers and the motivations for contraceptive advice, with good reason. ${ }^{1}$ Individuals and networks exist within larger communities and cultures with rules, expectations, and norms relevant to HIV risk. These cultural factors often impact risk indirectly; their effects may be mediated by more proximal individual-level processes or they may moderate the effects of individuallevel processes. That is, some individual factors may be more or less important depending on the cultural context. Certain dyadic and community factors relevant to HIV risk are emergent properties of individual-level processes. For example, neighborhood collective efficacy emerges from individuals' beliefs about the importance of working together to improve a neighborhood and such neighborhood-level measures have been found to correlate with outcomes such as the prevalence of STI infections in the neighborhood. ${ }^{90-92}$

\section{Postulate 4: HIV Spreads through Networks}

A fourth and final postulate of an NIR model for HIV prevention builds on the first three: Like other communicable diseases, HIV is spread by the behaviors of individuals who are associated in one or more networks. It follows that individuals are safe from HIV except when one or more of their networks has high HIV prevalence. Even if they are members of a high prevalence network, an individual's risk will not elevate unless they engage in behaviors that exchange bodily fluids, which is the NIR model's relevance principle. Thus, consistent with the prior postulates, risk is elevated only when individual or network resources are low; when mental or tangible resources are aligned to support or permit unsafe 
behaviors. Thus, being a member of even one network with high HIV prevalence, that enact dyadic behaviors that exchange bodily fluids, and that has mental and tangible resources that foster risky behaviors means that members of this network are at high risk. Consequently, as a simple primary prevention principle, disrupting the membership of HIV-negative individuals from high-risk networks with high HIV prevalence reduces the individual's risk for HIV and should reduce HIV transmission; consonant with the first three postulates, the nature of disruption that takes place should be appropriate to the culture in question. It follows that high-HIV-prevalence networks that cease to exist disperse their remaining living members into other networks, consequently, increasing the risk of HIV infection to members of the "new" network to which they affiliate. Such a pattern may be especially prominent when mental or tangible resources are low. It also follows that the most important networks will be those whose members engage in behaviors known to transmit HIV. Thus, from a public health perspective, a more comprehensive approach to HIV prevention must embrace a secondary prevention principle, which is that those living with HIV must be made aware of their status and provided with sufficient resources to cope with disease and to prevent further transmission of HIV to other uninfected individuals. Indeed, many societies already provide resources for individuals living with HIV, meaning that knowledge of HIV status itself may become resource-enhancing and a means to survive and thrive. To the extent that such networks lack resources, then HIV-positive individuals are more likely to knowingly engage in HIV transmission behaviors when doing so permits them to meet needs that they find more important. ${ }^{93}$ These factors point to the need for early detection of HIV infection and prompt referral to medical treatment and HIV preventive counseling to augment tangible (i.e. care, ARVs) and mental resources (supportive counseling, case management).

Community incidence of pathogens that often co-occur with HIV (e.g., gonorrhea, syphilis, herpes simplex-2, Chlamydia) provides one mode of identification of individuals in risky networks that also will quickly transmit HIV once a member has it. Having identified these individuals, research should characterize the key individuals and their valued social networks and resources; then, prevention messages can be designed to reflect these elements and be delivered to or through these networks. This strategy would disrupt transmission of multiple infectious diseases and be more efficient than focusing only on HIV. The value added by an NIR perspective comes most into focus when considering examples in which network characteristics may be critical to understanding HIV epidemiology. For example, African American young MSM disproportionately bear the burden of HIV in the U.S., with more than twice the number of HIV infections as white young MSM, despite representing only $17 \%$ of the adolescent population. ${ }^{46}$ Complicating this disparity is that multiple studies have found that African Americans young MSM do not report more occasions of unprotected sex or injection drug use. ${ }^{94,95}$ It has been suggested that to understand these disparities requires consideration of social network factors, such as partner age ${ }^{95}$ and racerelated partner preferences, ${ }^{96}$ as well as differences in tangible resources, such as access to HIV testing and STI treatment. ${ }^{95,97}$

Voluntary counseling and testing (VCT) can also serve as another method for identifying individuals who are at high risk of transmission and for identifying HIV-positive individuals 
who can transmit infection to others. In the past, VCT interventions have been criticized as costly and time-expensive, and as effective only for serodiscordant couples and individuals diagnosed as HIV-positive. ${ }^{98}$ Yet, from an NIR perspective and viewing VCT as an "entrypoint," there lies the potential for an integrated "follow-up" intervention targeted to individuals based on their serostatus that is sensitive and relevant to the sociocultural and economic needs of the individuals and their networks. Another option for trying to attain sustained prevention is the recruitment of individuals, post-VCT, into new networks that support safer sex as normative, such as HIV/AIDS advocacy groups and community organizations.

Because large networks are often mistrusted or seen as irrelevant to meeting important needs (the malevolence principle), targeting smaller, more trusted networks offers greater possibility of sustained change. Following the benevolence principle requires identifying the important networks of those living with HIV, which may result in optimally tailored messages to promote preventive behaviors and, thus, be more effective at reducing transmission of HIV. Such actions also best position individuals with the tangible resources (e.g., antiretroviral therapy) necessary to live with the disease. Knowledge of HIV status also should generally lower transmission, but as we have noted above, individuals who lack the mental and tangible resources necessary to cope with their serostatus may still knowingly engage in behaviors that transmit the disease. ${ }^{93}$ In such instances, economic and social interventions are also indicated as a long-term strategy to improve the network's sustainable mental and tangible resources.

\section{Summary}

The NIR model rests on four postulates to understand HIV risk behavior that occurs across settings that range from individual to collective. The postulates imply numerous principles (Table II), which in turn have many implications for HIV prevention. The model emphasizes that in order to halt the spread of HIV, prevention efforts must consider the ways in which individuals are tied to important networks. HIV prevention efforts themselves will be more successful when they rely on trusted networks or become trusted networks themselves. Thus, prevention efforts are more successful and sustainable when they (1) prompt behavior changes that can be sustained by the resources the individual or their networks possess; (2) meet individual and network needs and are consistent with the individual's current situation/ developmental stage; (3) are trusted and valued; and (4) target high HIV-prevalence networks.

\section{Critique and Future Directions}

In this concluding section, we (1) critique the NIR model, contrasting it with popularly employed HIV prevention frameworks, and (2) identify opportunities for future research and theoretical development relative to an NIR model. Throughout, we identify the model's strengths and weaknesses. 


\section{The NIR perspective relative to alternative theoretical viewpoints}

Table III compares selected individual theories of HIV prevention to the dimensions that an NIR model advances and considers most important. Commencing with its $1^{\text {st }}$ column, the dimension of mental resources, the NIR model is congenial to variables specified by such models as the Social Cognitive Theory, ${ }^{99,100}$ the Theories of Reasoned Action ${ }^{101}$ and Planned Behavior, ${ }^{102}$ the Transtheoretical Model, ${ }^{103,104}$ and the Information, Motivation, Behavioral Skills Model, ${ }^{105}$ including self-efficacy, intentions to act safely, and skills, among others. Meta-analytic reviews of HIV prevention interventions have documented robust effect sizes achieved almost entirely at the individual level across a range of groups (e.g., men who have sex with men [MSM], adolescents, people living with HIV/AIDS [PLWHA], African Americans), ${ }^{10-12,31,106,107}$ including those at highest risk. Similarly, individual-level research is also characterized by well-defined scientific procedures for selection, reach, research design and measurement, and analysis. ${ }^{32}$ Therefore, it would be unwise to disregard the strong advantages of efficacious individual-level work to date. Yet, the NIR model would extend the reach of these theories and models by encouraging evaluation of the mental resources of the individuals networked to members of particular groups at elevated risk for HIV (Postulate 3). It would also encourage embracing the conception that such variables as beliefs and attitudes are truly mental resources and, as such, may be viewed as valued possessions by those who possess them. ${ }^{108,109}$ Thus, the NIR model is cognizant that individual mental resources may be overwhelmed by powerful other entities; of course, unless these entities are evaluated, their impact will be overlooked. The dimension of perceived behavioral control may reflect perceptions of power dynamics within relationships and networks, or possibly other factors. We develop this theme in the next sub-section.

The NIR model explicitly considers the role of tangible resources as a necessary condition to sustain mental resources (Postulates 1 and 2). In contrast, as the $2^{\text {nd }}$ column in Table III shows, popular models of HIV prevention consider tangible resources indirectly or only imply that they might be important; none of these models explicitly states that mental resources must be sustained with sufficient tangible resources. Nor do they explicitly predict that people will be more susceptible to infection to the extent that they lack tangible resources and engage in HIV risk behaviors, as the NIR model does (e.g., disparity principle). Instead, current theories and models consider that individuals may possess mental resources regarding tangible resources (e.g., an attitude toward using condoms), but they do not directly consider how the resources that others possess may bear on HIV risk. Of note, a recent systematic review found only 6 couples-focused behavioral interventions for the prevention of HIV; ${ }^{110}$ in contrast, there are hundreds of controlled interventions that evaluate individual-focused efforts. ${ }^{10,106,111}$ An NIR perspective implies that future interventions must take the individuals' substantive ties to networks more seriously instead of focusing merely on individuals. As stated at the outset, extant scholarship has generally overlooked ties between levels of analysis ranging from the individual to the collective. This omission must be rectified and the resulting new research will no doubt refine an NIR model. 
The NIR model's explicit focus on resources (Postulates 1,2, and 3) is a strength because poverty clearly plays such a prominent role creating an environment that facilitates transmission of HIV. Yet, this emphasis may be seen as a weakness because so many experts consider conditions of poverty unchangeable. For example, only until recently did Haiti's economy emerge from decades of support from other countries such as the U.S., only to suffer a huge setback with the January 2010 earthquake; the NIR model predicts that without further large contributions to restore the country's infrastructure, HIV and other diseases will proliferate further crippling the country. In identifying resource constraints that make prevention efforts fail, the NIR model may seem to make rather daunting predictions. Yet, the global HIV epidemic itself has proven daunting, and focusing on the ultimate causes of the epidemic seems imperative. ${ }^{112}$

Beyond identifying tangible resources as important, an NIR perspective encourages a recognition that people to some extent own their networks (and vice versa) as possessions or resources in and of themselves. The NIR model's emphasis on resource-based coping in the face of stressors is consistent with such health behavior models as Social Action Theory ${ }^{113}$ and the Conservation of Resources Model ${ }^{114}$; it is also consonant with work on a specific network, marital relationships, as exemplified by Vulnerability-Stress-Adaptation Model of Marital Satisfaction. ${ }^{115}$ Like this latter model, an NIR perspective offers micro-macro linkages in recognizing that important processes occur both within individuals and in the interactions with their important networks.

Because individual and structural elements clearly are relevant to HIV risk and prevention of HIV transmission, a strength of the NIR model is that it recognizes the linkage between the micro and macro level (Table III, $3^{\text {rd }}$ column), where micro connotes processes or variables solely within individuals and macro implies linkages between individuals and others. ${ }^{115}$ Thus, the NIR model recognizes the individuals (micro) enact risk behaviors with those linked in networks (macro). (We consider factors that may be even more "structural" below.) In contrast, other HIV prevention theories either have no explicit linkage to macro levels or do so only indirectly. The Social Cognitive Model includes the environment via reciprocal determinism, but does not specify explicit macro linkages. ${ }^{99,100}$ The Theories of Reasoned Action ${ }^{101}$ and Planned Behavior ${ }^{102}$ take a micro focus but include descriptive and injunctive subjective norms, which may reflect the realities of others important to the individual. The Transtheoretical Model takes a micro focus with no explicit macro linkages except that helping relationships, social liberation, and environmental re-evaluation are assessed at individual level, and individual support for social policies provides another bridge across levels. ${ }^{104}$ Again, there is no assurance that the realities match perceptions. Finally, the Information, Motivation, Behavioral Skills Model ${ }^{105}$ is micro but, if elicitation research identifies macro as important, then it recommends targeting these levels, as well (e.g., safer sex negotiation skills). Although some of these models gauge perceptions of social reality as viewed by the individual, none of them explicitly spell out how the realities match individual perceptions or directly consider how these realities interplay with the targeted individuals.

Through its resource-based linkages of individuals to their important networks, the NIR model is collective, which permits it to bridge broader social perspectives such as 
economics, sociology, anthropology, and political science; its focus on resources also makes it compatible to disciplines with a similar emphasis (e.g., economics, political science). It is similar to ecological viewpoints in urging a careful analysis of the resources available in the social milieus surrounding individuals, ${ }^{33,116,117}$ but different in that it specifies reciprocal exchanges and relationships between individuals and their networks as the important process underlying risk behavior and its change. ${ }^{118}$ It is compatible to ecological models in focusing on the interface between needs and resources.

Prior HIV prevention models also have difficulty explaining the passive influences that socalled structural interventions may have on risk behaviors (Table III, right-most column). For example, needle-exchange programs succeed more because drug users' environments facilitate access to and use of an important tangible resource-new, uninfected needlesand less because of changes in drug users' mental resources. Similarly, micro-economic interventions succeed not through changing individual mental resources, but by changing the economic (tangible) resources that enable an individual to avoid risk situations or refuse engaging in HIV risk behaviors. ${ }^{117}$ Except for the NIR model, which has an explicit role for tangible resources, none of Table III's models can explain such effects (right-most column). Indeed, some of the models even predict that such structural changes are mediated through changes in variables that underlie intentions to engage in the behavior (e.g., attitudes, subjective norms, efficacy).The NIR model, in contrast, asserts that networks create structural realities through resource provision and exchange that may have their impact on risk behaviors in either direct or indirect fashion, consistent with the active and passive prevention principles (Postulate 1; Table I, right-most column). The caveat, of course, is that impacting a small network will not on its own routinely have a detectable impact on related larger networks. Reducing risk in a network of adolescents within a community through a condom distribution program is likely only to impact on this network, not on their other family members or alternative networks of adolescents, unless resource-enabled bridges to these other networks are also established and nurtured. Similarly, highly powered networks - those with high tangible and mental resources-have the potential reach to impact all networks in a society, creating deep structural changes (see Table I, lower right corner). From an NIR perspective, therefore, structural interventions might be defined as relatively large networks effecting changes to the mental or tangible resources of their membership. Yet an NIR perspective also recognizes that even small networks create structural realities for their members that often can have profound effects on risk behaviors.

This comparison of the NIR model to extant models might be viewed as selective, as only a sampling of contemporary models appeared. ${ }^{119}$ In general, alternative models suffer the same limitations that we have listed in this sub-section, but there are exceptions, largely deriving from sociological rather than psychological traditions, or attempting to bridge from psychological to sociological perspectives. First, the NIR model's emphasis on the mental resources that networks wield is generally consonant with Social Capital Theory, ${ }^{120,121}$ except that the NIR model goes beyond social capital (mental) to embrace the tangible as well. The NIR model's implication that network ties can have a positive or negative valence is consistent with critics' claims that social capital can have negative effects. ${ }^{122}$ Finally, 
Social Capital Theory offers no predictions for behavior change and no direct implications for mechanisms underlying behavior change.

Another model that has taken important steps in the direction of including social and more structural influences and relationships is the Multiple Domain Model, ${ }^{123}$ which includes direct paths between social structural factors and all outcomes including behavior. It includes the social-cultural environment as one of the domains of the model that can be both affected by social structural variables and affect social psychological mediators and behavioral outcomes, and includes situational/contextual factors. Yet, to date, the model has focused only indirectly on links beyond individuals (assessed through the eyes of the individual) and it does not directly consider the role of resources, similar to the other theories in Table III.

Also compatible with the NIR model is the Theory of Gender and Power (TGP). ${ }^{86,124}$ This theory highlights the fact that in most societies males often have more power than females, a dynamic that we have highlighted. According to TGP, this inequity is embedded in societal and institutional levels that empower males more than females. Although TGP itself is not a theory of behavior change, those who have developed it make recommendations that are consonant with the NIR model. For example, Wingood and DiClemente ${ }^{86}$ operationalized the TGP for guiding the development and implementation of HIV interventions and recommended, among other things, to define the community of at-risk women (e.g., Hispanic women), identify exposures and risk factors for HIV, and after sharing this information with the community, involve its members to determine strategies of influence. The NIR model goes beyond the TGP to identify specific mechanisms of behavior change.

\section{Future directions in research on networks, individuals, and resources}

Our goal in outlining the NIR model was to combine individual and broader perspectives in a cohesive HIV prevention model; such a model offers the hope of greater and sustainable prevention success by focusing on the capacities of the individuals and their important networks. From this perspective, one of the NIR model's greatest strengths is that whereas it has relatively few general postulates, these combine to create interesting implications for HIV prevention. Yet it also presents challenges for future research on networks, individuals, and resources because to date so little research has investigated all of these factors simultaneously. It will be important for future researchers to develop better methods to assess the important facets of the model. Of particular importance will be enhanced methods of (1) detecting the important networks of individuals in targeted risk groups, (2) learning what resources they share, and (3) determining what needs are chronically most pressing. Currently, a weakness of the NIR model is that it does not identify, a priori, what needs would be the most important at a given point in time for a particular individual or network. Moreover, much work remains to be done describing, intervening on, and understanding the moderating effects of important network characteristics for specific at-risk populations and settings. This work can provide the foundation for quantitative evaluations and interventions conducted on a large enough scale to impact at risk populations. In the absence of extant empirical evidence, the NIR model builds on others' suggestions that HIV prevention theory would benefit from more attention to relationship factors ${ }^{125,126}$ and social 
networks $2,68,127,128$ as resources. ${ }^{114}$ The complexity of the interplay between individuals and their networks requires a theoretical and methodological approach that can accommodate multilevel interactions; interactions that are reciprocal between the individual and their network. ${ }^{116,129}$ Finally, because the interactions between individuals and their networks may be fleeting and highly changeable, it will be critical to introduce temporal variables, including multiple measures over time, into this research. ${ }^{130-132}$

Meta-analyses of existing prevention research already are pursuing the implications of an NIR model by examining how structural-level variables (e.g., human development index, Gini coefficient) relate to prevention outcomes. For example, Huedo-Medina and colleagues ${ }^{133}$ documented that intensive behavioral HIV interventions were more successful in poorer rather than richer nations in Latin America and the Caribbean; consistent with the NIR model, one explanation is that interventions succeed best where need is greatest. Another explanation, also consistent with the NIR model, is that people living in nations with fewer resources have more mental resource needs (e.g., knowledge). Original primarylevel research is also be desirable, but could well prove prohibitively costly if fully instantiated. That is, including complex assessments of all relevant networks and their resources may add significant cost, time, and resource demands to project staff and to study participants that make it both more difficult to conduct and to fund such studies. It may therefore be useful to determine when individuals' perceptions of their important networks and the behavior of their network members may be sufficient substitutes for actual network assessment, which would be less resource-intensive. It is likely that different measures are best for different purposes (e.g., affecting networks, understanding the moderating role of networks in interventions, predicting longitudinal behavior change). Similarly, it may be useful to assess under which conditions individuals' perceptions of neighborhood, community, and cultural variables may be adequate or perhaps stronger determinants of behavior change than the "objective" reality of variables measured at levels higher than that of the individual (i.e. actual community norms regarding condom use). Perhaps under certain circumstances we can capture those important network or structural variables with data collected from individuals and have enough important information to inform our interventions without the significant added cost and demands of the more complex data collection process.

\section{Conclusion}

The NIR model embraces the critical role that resources play in satisfying pressing needs through the interplay of individuals with their important social networks - unlike other HIV prevention models. At its core, the NIR model considers how individuals cope with their stressors through networks of other individuals, how they share resources with each other to meet their individual or shared needs, and how these factors interface with transmission of HIV. It urges a careful focus on the capacities that individuals and their networks have and how these capacities relate to HIV risk. Future research will need to examine the strengths and weaknesses that we have identified in this developmental paper, and especially to determine how much of an advantage accrues to prevention outcomes by increasing a focus on the critical networks surrounding individuals and by understanding what resources are most needed. Nevertheless, the NIR model for HIV prevention offers a new perspective and 
opens new research avenues, asks broader questions, requires new data, and, importantly, offers considerable hope of averting greater numbers of infections and improving public health by more appropriately and effectively involving individuals and social networks in the prevention process. These factors will also be important to incorporate in instantiating any medical intervention (e.g., vaccine programs), as these also hinge on networks of individuals exchanging resources. It follows that an NIR perspective such as we have elaborated here may also prove valuable in understanding and solving other public health problems that hinge on the behaviors of individuals interacting in social networks.

\section{Acknowledgments}

This article is dedicated to the memory of Martin Fishbein (1936-2009), our colleague and friend, whose commitment to theory-building, research and HIV prevention continue to inspire those who were networked with him and those who will symbolically do so into posterity.

The preparation of this article was supported in part by NIMH grant R13-MH080619 and benefitted from comments provided by attendees at the conference that it funded. Dolores Albarracín, Marijn de Bruin, Tania B. Huedo-Medina, and two anonymous reviewers also provided helpful commentary.

\section{References}

1. Friedman SR, Cooper HL, Osborne AH. Structural and social contexts of HIV risk Among African Americans. Am J Public Health. Jun; 2009 99(6):1002-1008. [PubMed: 19372519]

2. Latkin CA, Knowlton AR. Micro-social structural approaches to HIV prevention: a social ecological perspective. AIDS Care. Jun; 2005 17(Suppl 1):S102-113. [PubMed: 16096122]

3. Salazar LF, Bradley EL, Younge SN, et al. Applying ecological perspectives to adolescent sexual health in the United States: rhetoric or reality? Health Educ Res. Dec 9.2009

4. Conner, M.; Norman, P., editors. Predicting health behaviour: research and practice with social cognition models. 2nd. Maidenhead: Open University Press; 2005.

5. Fishbein, M.; Triandis, H.; Kanfer, F.; Becker, M.; Middlestadt, S.; Eichler, A. Factors influencing behavior and behavior change. In: Baum, A.; Revenson, T.; Singer, J., editors. Handbook of Health Psychology. Mahwah: Erlbaum; 2001. p. 3-17.

6. Noar S, Zimmerman R. Health behavior theory and cumulative knowledge regarding health behaviors: are we moving in the right direction? Health Educ Res. 2005; 20(3):275-290. [PubMed: 15632099]

7. Mustanski B, Viken RJ, Kaprio J, Winter T, Rose RJ. Sexual behavior in young adulthood: a population-based twin study. Health Psychol. Sep; 2007 26(5):610-617. [PubMed: 17845112]

8. Albarracin D, Johnson BT, Fishbein M, Muellerleile PA. Theories of reasoned action and planned behavior as models of condom use: a meta-analysis. Psychol Bull. 2001; 127(1):142-161. [PubMed: 11271752]

9. Sheeran P, Abraham C, Orbell S. Psychosocial correlates of heterosexual condom use: a metaanalysis. Psychol Bull. Jan; 1999 125(1):90-132. [PubMed: 9990846]

10. Albarracin D, Gillette JC, Earl AN, Glasman LR, Durantini MR, Ho MH. A test of major assumptions about behavior change: a comprehensive look at the effects of passive and active HIV-prevention interventions since the beginning of the epidemic. Psychol Bull. Nov; 2005 131(6):856-897. [PubMed: 16351327]

11. Webb TL, Sheeran P. Does Changing Behavioral Intentions Engender Behavior Change? A MetaAnalysis of the Experimental Evidence. Psychol Bull. 2006; 132(2):19p.

12. Johnson BT, Carey MP, Marsh KL, Levin KD, Scott-Sheldon LAJ. Interventions to reduce sexual risk for the human immunodeficiency virus in adolescents, 1985-2000: A research synthesis. Arch Pediatr Adolesc Med. Apr; 2003 157(4):381-388. [PubMed: 12695235]

13. Bastos FI, Strathdee SA. Evaluating effectiveness of syringe exchange programmes: current issues and future prospects. Soc Sci Med. Dec; 2000 51(12):1771-1782. [PubMed: 11128265] 
14. Bauermeister JA, Tross S, Ehrhardt AA. A review of HIV/AIDS system-level interventions. AIDS Behav. Jun; 2009 13(3):430-448. [PubMed: 18369722]

15. Volmink J. Mother to child transmission of HIV. Clin Evid. Jun.2002 (7):709-716. [PubMed: 12230698]

16. Smith KP, Christakis NA. Social networks and health. Annu Rev Sociol. 2008; 34:405-429.

17. Loewenson R, Hadingham J, Whiteside A. Household impacts of AIDS: using a life course approach to identify effective, poverty-reducing interventions for prevention, treatment and care. AIDS Care. Aug; 2009 21(8):1032-1041. [PubMed: 20024760]

18. UNAIDS. 2004 Report on the Global HIV/AIDS Epidemic. Geneva, Switzerland: UNAIDS; 2004.

19. WHO. The World Health Report 2004: Changing History. Geneva, Switzerland: World Health Organization; 2004.

20. Merson MH, O'Malley J, Serwadda D, Apisuk C. The history and challenge of HIV prevention. Lancet. Aug 9; 2008 372(9637):475-488. [PubMed: 18687461]

21. Bene C, Merten S. Women and Fish-for-Sex: Transactional Sex, HIV/AIDS and Gender in African Fisheries. World Dev. 2008; 36(5):25p.

22. Cloete A, Simbayi LC, Kalichman SC, Strebel A, Henda N. Stigma and discrimination experiences of HIV-positive men who have sex with men in Cape Town, South Africa. AIDS Care. Oct; 2008 20(9):1105-1110. [PubMed: 18608067]

23. Hunter M. The changing political economy of sex in South Africa: the significance of unemployment and inequalities to the scale of the AIDS pandemic. Soc Sci Med. Feb; 2007 64(3): 689-700. [PubMed: 17097204]

24. Kalichman SC, Simbayi LC, Kagee A, et al. Associations of poverty, substance use, and HIV transmission risk behaviors in three South African communities. Soc Sci Med. Apr; 2006 62(7): 1641-1649. [PubMed: 16213078]

25. Simbayi LC, Kalichman S, Strebel A, Cloete A, Henda N, Mqeketo A. Internalized stigma, discrimination, and depression among men and women living with HIV/AIDS in Cape Town, South Africa. Soc Sci Med. 2007; 64(9):9p.

26. UNAIDS. Gender and HIV/AIDS: Taking Stock of Research and Programmes. Geneva, Switzerland: UNAIDS; 1999.

27. Mansson F, Biague A, da Silva ZJ, et al. Prevalence and incidence of HIV-1 and HIV-2 before, during and after a civil war in an occupational cohort in Guinea-Bissau, West Africa. AIDS. Jul 31; 2009 23(12):1575-1582. [PubMed: 19521234]

28. Udoh IA, Mantell JE, Sandfort T, Eighmy MA. Potential pathways to HIV/AIDS transmission in the Niger Delta of Nigeria: poverty, migration and commercial sex. AIDS Care. May; 2009 21(5): 567-574. [PubMed: 19444664]

29. DiClemente RJ, Wingood GM, Blank MB, Metzger DS. Future directions for HIV prevention research: charting a prevention science research agenda. J Acquir Immune Defic Syndr. Mar 1; 2008 47(Suppl 1):S47-48. [PubMed: 18301134]

30. Noar SM, Benac CN, Harris MS. Does tailoring matter? Meta-analytic review of tailored print health behavior change interventions. Psychol Bull. Jul; 2007 133(4):673-693. [PubMed: 17592961]

31. Johnson BT, Scott-Sheldon LA, Smoak ND, Lacroix JM, Anderson JR, Carey MP. Behavioral interventions for African Americans to reduce sexual risk of HIV: a meta-analysis of randomized controlled trials. J Acquir Immune Defic Syndr. Aug 1; 2009 51(4):492-501. [PubMed: 19436218]

32. Fisher, J.; Fisher, W. Theoretical approaches to individual-level change in HIV-risk behavior. In: Peterson, J.; DiClemente, R., editors. HIV Prevention Handbook. New York: Kluwer Academic/ Plenum Press; 2000. p. 3-55.

33. Piot P, Bartos M, Larson H, Zewdie D, Mane P. Coming to terms with complexity: a call to action for HIV prevention. Lancet. Sep 6; 2008 372(9641):845-859. [PubMed: 18687458]

34. Cohen S, Janicki-Deverts D. Can we improve our physical health by altering our social networks? Perspect Psychol Sci. 2009; 4(4):375-378. [PubMed: 20161087]

35. Wiessing L, Likatavicius G, Klempova D, Hedrich D, Nardone A, Griffiths P. Associations between availability and coverage of HIV-prevention measures and subsequent incidence of 
diagnosed HIV infection among injection drug users. Am J Public Health. Jun; 2009 99(6):1049_ 1052. [PubMed: 19372511]

36. Human Development Report 2007/2008. New York: United Nations Development Programme; 2007. UNDP.

37. McAlister AR, Pachana N, Jackson CJ. Predictors of young dating adults' inclination to engage in extradyadic sexual activities: A multi-perspective study. Br J Psychol. 2005; 96(3):20p.

38. Roscoe B, Cavanaugh LE, Kennedy DR. Dating infidelity: behaviors, reasons and consequences. Adolescence. Spring;1988 23(89):35-43. [PubMed: 3381685]

39. Rhodes T, Singer M, Bourgois P, Friedman SR, Strathdee SA. The social structural production of HIV risk among injecting drug users. Soc Sci Med. Sep; 2005 61(5):1026-1044. [PubMed: 15955404]

40. Gibbons FX, Eggleston TJ. Smoker networks and the "typical smoker": a prospective analysis of smoking cessation. Health Psychol. Nov; 1996 15(6):469-477. [PubMed: 8973928]

41. Unger JB, Chen X. The role of social networks and media receptivity in predicting age of smoking initiation: a proportional hazards model of risk and protective factors. Addict Behav. May-Jun; 1999 24(3):371-381. [PubMed: 10400276]

42. Papacrhistos AV. Murder by structure: Dominance relations and the social structure of gang homicide. Am J Sociol. 2009; 115:74-128. [PubMed: 19852186]

43. Moreland, R.; Levine, J. Advances in Experimental Social Psychology. Vol. 15. New York: Academic Press; 1982. Socialization in small groups: temporal changes in individual group relations. In: Berkowitz L, ed; p. 137-192.

44. Mayer KH, Bradford JB, Makadon HJ, Stall R, Goldhammer H, Landers S. Sexual and gender minority health: what we know and what needs to be done. Am J Public Health. Jun; 2008 98(6): 989-995. [PubMed: 18445789]

45. Rosser B, Oakes J, Bockting W, Miner M. Capturing the social demographics of the transgender population in the United States. Sex Res Social Policy. 2007; 4(2):50-64.

46. CDC. Trends in HIV/AIDS diagnoses among men who have sex with men--33 states, 2001-2006. MMWR Morb Mortal Wkly Rep. 2008; 57(25):681-686. [PubMed: 18583954]

47. Sullivan PS, Hamouda O, Delpech V, et al. Reemergence of the HIV Epidemic Among Men Who Have Sex With Men in North America, Western Europe, and Australia, 1996-2005. Ann Epidemiol. 2009; 19(6):9.

48. Wagner GJ, Remien RH. Prevalence of Extradyadic Sex in Male Couples of Mixed HIV Status and Its Relationship to Psychological Distress and Relationship Quality. J Homosex. 2000; 39(2):16.

49. Remien, R.; Morin, S.; Lightfoot, M.; Weinhardt, L.; Ehrhardt, A. Sexual risk: behaviors, attitudes, and meaning among a diverse sample of HIV-seropositive adults in four US cities; Paper presented at: National HIV Prevention Conference; 2001; Atlanta, GA.

50. Hays RB, Rebchook GM, Kegeles SM. The Mpowerment Project: community-building with young gay and bisexual men to prevent HIV1. Am J Community Psychol. Jun; 2003 31(3-4):301-312. [PubMed: 12866687]

51. Kegeles SM, Hays RB, Coates TJ. The Mpowerment Project: a community-level HIV prevention intervention for young gay men. Am J Public Health. Aug; 1996 86(8):1129-1136. [PubMed: 8712273]

52. Kegeles SM, Hays RB, Pollack LM, Coates TJ. Mobilizing young gay and bisexual men for HIV prevention: a two-community study. AIDS. Sep 10; 1999 13(13):1753-1762. [PubMed: 10509578]

53. Kohler PK, Manhart LE, Lafferty WE. Abstinence-only and comprehensive sex education and the initiation of sexual activity and teen pregnancy. J Adolesc Health. Apr; 2008 42(4):344-351. [PubMed: 18346659]

54. Chigwedere P, Seage GR 3rd, Gruskin S, Lee TH. Estimating the lost benefits of antiretroviral drug use in South Africa. J Acquir Immune Defic Syndr. Dec 1; 2008 49(4):410-415. [PubMed: 19186354]

55. Blum RW. Uganda AIDS prevention: A,B,C and politics. J Adolesc Health. May; 2004 34(5):428432. [PubMed: 15093799] 
56. Wolitski, RJ.; Stall, R.; Valdiserri, RO., editors. Unequal Opportunity: Health Disparities Affecting Gay and Bisexual Men in the United States. Oxford: Oxford University Press; 2007.

57. Meyer IH. Prejudice, social stress, and mental health in lesbian, gay, and bisexual populations: conceptual issues and research evidence. Psychol Bull. 2003; 129(5):674-697. [PubMed: 12956539]

58. Diamant AL, Wold C. Sexual orientation and variation in physical and mental health status among women. J Womens Health (Larchmt). Jan-Feb;2003 12(1):41-49. [PubMed: 12639368]

59. Dodge, B.; Sandfort, TGM. A review of mental health research on bisexual individuals when compared to homosexual and heterosexual individuals. In: Firestein, BA., editor. Becoming Visible: Counseling Bisexuals Across the Lifespan. New York: Columbia University Press; 1997. p. 28-51.

60. Garofalo R, Wolf RC, Wissow LS, Woods ER, Goodman E. Sexual orientation and risk of suicide attempts among a representative sample of youth. Arch Pediatr Adolesc Med. May; 1999 153(5): 487-493. [PubMed: 10323629]

61. Meyer IH. Minority stress and mental health in gay men. J Health Soc Behav. Mar; 1995 36(1):3856. [PubMed: 7738327]

62. Paul JP, Catania J, Pollack L, et al. Suicide attempts among gay and bisexual men: lifetime prevalence and antecedents. Am J Public Health. Aug; 2002 92(8):1338-1345. [PubMed: 12144994]

63. Marshal MP, Friedman MS, Stall R, et al. Sexual orientation and adolescent substance use: a metaanalysis and methodological review. Addiction. Apr; 2008 103(4):546-556. [PubMed: 18339100]

64. Mustanski B, Garofalo R, Herrick A, Donenberg G. Psychosocial health problems increase risk for HIV among urban young men who have sex with men: preliminary evidence of a syndemic in need of attention. Ann Behav Med. Aug; 2007 34(1):37-45. [PubMed: 17688395]

65. Stall R, Mills TC, Williamson J, et al. Association of co-occurring psychosocial health problems and increased vulnerability to HIV/AIDS among urban men who have sex with men. Am J Public Health. Jun; 2003 93(6):939-942. [PubMed: 12773359]

66. UNAIDS. Report on the Global HIV/AIDS Epidemic. Geneva: Joint United Nations Programme on HIV/AIDS (UNAIDS); 2008.

67. Obermeyer CM, Osborn M. The utilization of testing and counseling for HIV: a review of the social and behavioral evidence. Am J Public Health. Oct; 2007 97(10):1762-1774. [PubMed: 17761565]

68. Rogers, EM. Diffusion of Innovations. 3rd. New York: The Free Press; 1983.

69. Stanton B, Cole M, Galbraith J, et al. Randomized trial of a parent intervention: parents can make a difference in long-term adolescent risk behaviors, perceptions, and knowledge. Arch Pediatr Adolesc Med. Oct; 2004 158(10):947-955. [PubMed: 15466681]

70. Stanton B, Fang X, Li X, Feigelman S, Galbraith J, Ricardo I. Evolution of risk behaviors over 2 years among a cohort of urban African American adolescents. Arch Pediatr Adolesc Med. Apr; 1997 151(4):398-406. [PubMed: 9111440]

71. Wu Y, Stanton BF, Galbraith J, et al. Sustaining and Broadening Intervention Impact: A Longitudinal Randomized Trial of 3 Adolescent Risk Reduction Approaches. Pediatrics. 2003; 111(1):7.

72. Valente TW, Okamoto J, Pumpuang P, Okamoto P, Sussman S. Differences in perceived implementation of a standard versus peer-led interactive substance abuse prevention program. Am J Health Behav. 2007; 2007(31):3.

73. Noguchi K, Albarracin D, Durantini MR, Glasman LR. Who participates in which health promotion programs? A meta-analysis of motivations underlying enrollment and retention in HIVprevention interventions. Psychol Bull. Nov; 2007 133(6):955-975. [PubMed: 17967090]

74. Pratto, F.; Lee, I.; Tan, JY.; Pitpitan, E. Power Basis Theory: A psycho-ecological approach to power. In: Dunning, D., editor. Social Motivation. New York: Psychology Press; 2010.

75. Kaiser Family Foundation. [Accessed 2009] Women and HIV/AIDS in the United States. 2008. http://www.kff.org/hivaids/upload/6092-04.pdf 
76. Wenzel S, Tucker J, Elliott M, Hambarsoomian K. Sexual risk among impoverished women: understanding the role of housing status. AIDS Behav. 2007; 11(Supp. 2):9-20. [PubMed: 17160485]

77. Gangakhedkar RR, Bentley ME, Divekar AD, et al. Spread of HIV infection in married monogamous women in India. JAMA. Dec 17; 1997 278(23):2090-2092. [PubMed: 9403424]

78. Lane SD, Rubinstein RA, Keefe RH, et al. Structural violence and racial disparity in HIV transmission. J Health Care Poor Underserved. Aug; 2004 15(3):319-335. [PubMed: 15453172]

79. Padian NS, Shiboski SC, Jewell NP. Female-to-male transmission of human immunodeficiency virus. JAMA. Sep 25; 1991 266(12):1664-1667. [PubMed: 1886189]

80. Amaro H. Love, sex, and power. Considering women's realities in HIV prevention. Am Psychol. Jun; 1995 50(6):437-447. [PubMed: 7598292]

81. Huda S. Sex trafficking in South Asia. Int J Gynaecol Obstet. Sep; 2006 94(3):374-381. [PubMed: 16846602]

82. Upchurch DM, Kusunoki Y. Associations between forced sex, sexual and protective practices, and sexually transmitted diseases among a national sample of adolescent girls. Womens Health Issues. 2004; 14(3):10p.

83. Wilson HW, Widom CS. An examination of risky sexual behavior and HIV in victims of child abuse and neglect: a 30-year follow-up. Health Psychol. Mar; 2008 27(2):149-158. [PubMed: 18377133]

84. Wyatt GE, Myers HF, Loeb TB. Women, Trauma, and HIV: an overview. AIDS Behav. Dec; 2004 8(4):401-403. [PubMed: 15690113]

85. Epstein, H. The Invisible Cure: Africa, the West, and the Fight Against AIDS. New York: Farrar Straus \& Giroux; 2007.

86. Wingood GM Scd, DiClemente RJ. Application of the theory of gender and power to examine HIV-related exposures, risk factors, and effective interventions for women. Health Educ Behav. Oct; 2000 27(5):539-565. [PubMed: 11009126]

87. Ehrhardt AA, Sawires S, McGovern T, Peacock D, Weston M. Gender, empowerment, and health: what is it? How does it work? J Acquir Immune Defic Syndr. Jul 1; 2009 51(Suppl 3):S96-S105. [PubMed: 19553784]

88. DiClemente RJ, Wingood GM. A randomized controlled trial of an HIV sexual risk-reduction intervention for young African-American women. JAMA. Oct 25; 1995 274(16):1271-1276. [PubMed: 7563531]

89. Wingood GM, DiClemente RJ. The ADAPT-ITT model: a novel method of adapting evidencebased HIV Interventions. J Acquir Immune Defic Syndr. Mar 1; 2008 47(Suppl 1):S40-46. [PubMed: 18301133]

90. Browning CR, Leventhal T, Brooks-Gunn J. Neighborhood context and racial differences in early adolescent sexual activity. Demography. Nov; 2004 41(4):697-720. [PubMed: 15622950]

91. Cohen D, Spear S, Scribner R, Kissinger P, Mason K, Wildgen J. "Broken windows" and the risk of gonorrhea. Am J Public Health. Feb; 2000 90(2):230-236. [PubMed: 10667184]

92. Grady WR, Klepinger DH, Billy JO. The influence of community characteristics on the practice of effective contraception. Fam Plann Perspect. Jan-Feb;1993 25(1):4-11. [PubMed: 8432376]

93. Simoni JM, Pantalone DW. Secrets and safety in the age of AIDS: does HIV disclosure lead to safer sex? Top HIV Med. Oct-Nov;2004 12(4):109-118. [PubMed: 15516708]

94. Garofalo R, Mustanski B, Emerson E, Stauffer A. Race/ethnicity differences in HIV risk among young men who have sex with men. Journal of Urban Health.

95. Harawa NT, Greenland S, Bingham TA, et al. Associations of race/ethnicity with HIV prevalence and HIV-related behaviors among young men who have sex with men in 7 urban centers in the United States. J Acquir Immune Defic Syndr. Apr 15; 2004 35(5):526-536. [PubMed: 15021318]

96. Raymond HF, McFarland W. Racial mixing and HIV risk among men who have sex with men. AIDS Behav. Aug; 2009 13(4):630-637. [PubMed: 19479369]

97. MacKellar DA, Valleroy LA, Secura GM, et al. Unrecognized HIV infection, risk behaviors, and perceptions of risk among young men who have sex with men: opportunities for advancing HIV prevention in the third decade of HIV/AIDS. J Acquir Immune Defic Syndr. Apr 15; 2005 38(5): 603-614. [PubMed: 15793373] 
98. Weinhardt LS, Carey MP, Johnson BT, Bickham NL. Effects of HIV counseling and testing on sexual risk behavior: a meta-analytic review of published research, 1985-1997. Am J Public Health. Sep; 1999 89(9):1397-1405. [PubMed: 10474559]

99. Bandura, A. Social Foundations of Thought and Action: A Social Cognitive Theory. New Jersey: Prentice Hall, Inc.; 1986.

100. Bandura, A. Social cognitive theory and exercise of control over HIV infection. In: DiClemente, RJ.; Peterson, JL., editors. Preventing AIDS: Theories and methods of behavioral interventions. New York: Plenum Press; 1994. p. 25-59.

101. Fishbein, M.; Ajzen, I. Belief, attitude, intention and behavior: An introduction to theory and research. Reading, MA: Addison-Wesley; 1975.

102. Ajzen I, Madden TJ. Prediction of goal-directed behavior: Attitudes, intentions and perceived behavioral control. J Exp Soc Psychol. 1986; 22:453-474.

103. Prochaska JO, Velicer WF. The transtheoretical model of health behavior change. Am J Health Promot. Sep-Oct;1997 12(1):38-48. [PubMed: 10170434]

104. Prochaska, J.; Redding, C.; Evers, K. The transtheoretical model and stages of change. In: Glanz, K.; Rimer, B.; Viswanath, K., editors. Health Behavior and Health Education: Theory, Research, and Practice. 4th. San Francisco: Jossey-Bass Inc.; 2008. p. 170-222.

105. Fisher JD, Fisher WA. Changing AIDS-risk behavior. Psychol Bull. May; 1992 111(3):455-474. [PubMed: 1594721]

106. Noar SM. Behavioral interventions to reduce HIV-related sexual risk behavior: review and synthesis of meta-analytic evidence. AIDS Behav. May; 2008 12(3):335-353. [PubMed: 17896176]

107. Johnson BT, Scott-Sheldon LA, Carey MP. Synthesis of meta-analytic evidence of health behavior change. Am J Public Health. In Press.

108. Johnson BT, Eagly AH. Effects of involvement on persuasion: A meta-analysis. Psychological Bulletin. 1989; 106(2):290-314.

109. Abelson RP. Beliefs are like possessions. Journal for the Theory of Social Behaviour. 1986; 16(3):223-250.

110. Burton J, Darbes LA, Operario D. Couples-focused behavioral interventions for prevention of HIV: systematic review of the state of evidence. AIDS Behav. Feb; 2010 14(1):1-10. [PubMed: 18843530]

111. Smoak ND, Scott-Sheldon LA, Johnson BT, Carey MP. Sexual risk reduction interventions do not inadvertently increase the overall frequency of sexual behavior: a meta-analysis of 174 studies with 116,735 participants. J Acquir Immune Defic Syndr. Mar; 2006 41(3):374-384. [PubMed: 16540941]

112. Coates TJ, Richter L, Caceres C. Behavioural strategies to reduce HIV transmission: how to make them work better. Lancet. Aug 23; 2008 372(9639):669-684. [PubMed: 18687459]

113. Ewart CK. Social action theory for a public health psychology. Am Psychol. Sep; 1991 46(9): 931-946. [PubMed: 1958012]

114. Hobfoll SE. Conservation of resources. A new attempt at conceptualizing stress. Am Psychol. Mar; 1989 44(3):513-524. [PubMed: 2648906]

115. Karney BR, Bradbury TN. The longitudinal course of marital quality and stability: a review of theory, method, and research. Psychol Bull. Jul; 1995 118(1):3-34. [PubMed: 7644604]

116. Bronfenbrenner U. Toward an experimental ecology of human development. Am Psychol. 1997; 32:513-531.

117. Pronyk PM, Hargreaves JR, Kim JC, et al. Effect of a structural intervention for the prevention of intimate-partner violence and HIV in rural South Africa: a cluster randomised trial. Lancet. Dec 2; 2006 368(9551):1973-1983. [PubMed: 17141704]

118. Thibaut, JW.; Kelley, HH. The social psychology of groups. New York: Wiley; 1959.

119. Noar SM. An interventionist's guide to AIDS behavioral theories. AIDS Care. Mar; 2007 19(3): 392-402. [PubMed: 17453575]

120. Coleman JS. Social capital in the creation of human capital. American Journal of Sociology. 1988; 94(S1):S95-S120. 
121. Putnam, RD. Bowling Alone: The Collapse and Revival of American Community. New York: Simon \& Schuster; 2000.

122. Larsen L, Harlan SL, Bolin B, et al. Bonding and bridging - Understanding the relationship between social capital and civic action. J Plan Educ Res. Fal;2004 24(1):64-77.

123. Zimmerman RS, Noar SM, Feist-Price S, et al. Longitudinal test of a multiple domain model of adolescent condom use. J Sex Res. Nov; 2007 44(4):380-394. [PubMed: 18321017]

124. Connell, RW. Gender and Power. Stanford, CA: Stanford University Press; 1987.

125. Canin L, Dolcini M, Adler N. Barriers to and facilitators of HIV-STD behavior change: intrapersonal and relationship-based factors. Rev Gen Psychol. 1999; 3(4):338-371.

126. Misovich S, Fisher J, Fisher W. Close relationships and elevated HIV risk behavior: evidence and possibly underlying psychological process. Rev Gen Psychol. 1997; 1(1):72-107.

127. Friedman SR, de Jong W, Rossi D, et al. Harm reduction theory: Users culture, micro-social indigenous harm reduction, and the self-organization and outside-organizing of users' groups. Int J Drug Policy. 2007; 18(2):107-117. [PubMed: 17689353]

128. Kelly JA. Popular opinion leaders and HIV prevention peer education: resolving discrepant findings, and implications for the development of effective community programmes. AIDS Care. 2004; 16(2):12p.

129. Poundstone KE, Strathdee SA, Celentano DD. The social epidemiology of human immunodeficiency virus/acquired immunodeficiency syndrome. Epidemiol Rev. 2004; 26:22-35. [PubMed: 15234945]

130. Bolger N, Davis A, Rafaeli E. Diary methods: capturing life as it is lived. Annu Rev Psychol. 2003; 54:579-616. [PubMed: 12499517]

131. Tennen H, Affleck G, Armeli S, Carney MA. A daily process approach to coping. Linking theory, research, and practice. Am Psychol. Jun; 2000 55(6):626-636. [PubMed: 10892205]

132. Tennen, H.; Affleck, G. Daily processes in coping with chronic pain: Methods and analytic strategies. In: Zeidner, M.; Endler, NS., editors. Handbook of Coping: Theory, Research, Applications. Oxford, England: John Wiley \& Sons; 1996.

133. Huedo-Medina TB, Boynton MH, Warren MR, Lacroix JM, Carey MP, Johnson BT. Efficacy of HIV Prevention Interventions in Latin American and Caribbean Nations, 1995-2008: A MetaAnalysis. AIDS Behav. Jul 27.2010 
Table I

Illustrations of mental and tangible resources present for units that vary in structural level; continuities of such variables over time enhance their value as resources to behavior; NIR model implications for HIV prevention efforts for each level.

\begin{tabular}{|c|c|c|c|c|}
\hline \multirow{2}{*}{\multicolumn{2}{|c|}{ Unit }} & \multicolumn{2}{|c|}{ Resource } & \multirow[b]{2}{*}{ HIV Prevention Efforts (at Each Level) } \\
\hline & & Mental & Tangible & \\
\hline \multicolumn{2}{|l|}{ Individual } & $\begin{array}{l}\text { Levels of variables necessary } \\
\text { for survival and thriving, such } \\
\text { as experiences integrated in } \\
\text { memory: attitudes, perceived } \\
\text { norms, perceived and actual } \\
\text { control over critical behaviors, } \\
\text { intentions and skills to enact } \\
\text { them }\end{array}$ & $\begin{array}{l}\text { Personal income, } \\
\text { possessions, physical health } \\
\text { (e.g., immune functioning, } \\
\text { parasite load), access to } \\
\text { medical care, life } \\
\text { expectancy, developmental } \\
\text { phase }\end{array}$ & $\begin{array}{l}\text { Provide resources important for individual } \\
\text { health; success is limited by level of trust } \\
\text { in efforts and extent of reach to all } \\
\text { relevant networks and by needs of } \\
\text { individual }\end{array}$ \\
\hline \multirow{4}{*}{ Network } & Intimate Dyadic & $\begin{array}{l}\text { Social support and trust, } \\
\text { relationship equity and power, } \\
\text { relationship satisfaction, acute } \\
\text { emotional rewards, } \\
\text { communication skills, } \\
\text { relationship health }\end{array}$ & $\begin{array}{l}\text { Partner income and joint } \\
\text { possessions, dyadic physical } \\
\text { health, life expectancy of } \\
\text { dyad }\end{array}$ & $\begin{array}{l}\text { Provide resources for protection of the } \\
\text { dyad's health; success is limited by trust } \\
\text { in efforts and the extent of their reach to } \\
\text { the pair's relevant networks and by the } \\
\text { needs of the dyad }\end{array}$ \\
\hline & Family & $\begin{array}{l}\text { Social support, trust, power } \\
\text { structure }\end{array}$ & $\begin{array}{l}\text { Shared possessions, } \\
\text { nurturance, family physical } \\
\text { health, network persists } \\
\text { based on mutual trust, } \\
\text { development phase }\end{array}$ & $\begin{array}{l}\text { Provides resources for protection of the } \\
\text { family's health; success is limited by trust } \\
\text { in the efforts and the extent of reach to the } \\
\text { family members' relevant networks and } \\
\text { by the needs of the family }\end{array}$ \\
\hline & Peers/Community & $\begin{array}{l}\text { Social capital (trust-based ties } \\
\text { of lower levels to networks), } \\
\text { shared norms and } \\
\text { expectations; possession and } \\
\text { wielding of power }\end{array}$ & $\begin{array}{l}\text { Shared possessions, network } \\
\text { existence hinges on } \\
\text { members' levels of trust and } \\
\text { membership engagement }\end{array}$ & $\begin{array}{l}\text { Provide resources for protection of the } \\
\text { network's health but limited by trust in the } \\
\text { efforts and the extent of reach to members } \\
\text { of the network }\end{array}$ \\
\hline & Society & $\begin{array}{l}\text { Education that affords } \\
\text { surviving and thriving; } \\
\text { tangible infrastructure that } \\
\text { affords safer mental and } \\
\text { physical health }\end{array}$ & $\begin{array}{l}\text { Pooled tangible resources } \\
\text { used to benefit network } \\
\text { members and allies; fiscal } \\
\text { health hinges on trust and } \\
\text { involvement of members, } \\
\text { power wielded by } \\
\text { stakeholders, or both }\end{array}$ & $\begin{array}{l}\text { Structural enhancements' success depend } \\
\text { on match to needs of the members and the } \\
\text { ecology in which they reside; they also } \\
\text { depend on trust in the agency that } \\
\text { institutes the activities }\end{array}$ \\
\hline
\end{tabular}




\section{Table II}

\section{Postulates and principles of a network-individual-resource (NIR) model of HIV prevention.}

INDIVIDUAL LEVEL: Preventive behavior depends on the need for, access to, value of, and interaction between mental and tangible resources

Postulate 1. Individuals cope with their environments by seeking and using tangible resources; they will behave safely when they possess safe mental and tangible resources, and unsafely when these resources are insufficient

- $\quad$ Empowerment Principle: Adequate mental and tangible resources enable safe behavior.

- Disparity Principle: Inadequate resources further contribute to HIV risk by hampering the efficacy of active, psychosocial educational prevention efforts

- Active Prevention Principle: Prevention efforts that ameliorate existing mental/tangible resource deficits will succeed better than those that ignore such deficits

Postulate 2. Individuals and networks value most the resources (tangible or mental) that satisfy their most pressing needs

- Situational-Developmental Prevention Principle: Because the nature of need varies widely across individuals and the lifespan, optimal prevention efforts must match the situation and developmental stage of the individual

NETWORK LEVEL: Preventive behavior depends on the interaction of the above stated individual-level postulates and network-level resources and influences.

Postulate 3. Networks serve as a resource for individuals, who are in turn also a resource for networks. Trust in and value of a network depends on the extent that the network facilitates coping in relation to the individual's inputs and resources, while an individual's importance to a network depends on the extent he/she provides the network important resources

- Benevolence Principle: Prevention efforts should succeed better to the extent that participants trust the providers and participation is voluntary, especially when other resources are sufficiently supportive

- Malevolence Principle: Prevention efforts will fail when participants do not trust providers, participation is involuntary, and/or when other resources increase risk

- Passive Prevention Principle: Networks with sufficient resources may enact changes that facilitate or hinder HIV prevention, regardless of the degree of trust held by network members

Postulate 4. HIV is spread through behaviors of individuals who are associated in one or more networks

- Relevance Principle: Networks with higher seroprevalence and greater substantive connections are of most concern for HIV prevention efforts.

- $\quad$ Primary Prevention Principle: Individual risk for HIV and HIV transmission will be reduced to the extent that membership of HIVnegative individuals in high HIV-prevalent networks is disrupted. Likewise, informing and mobilizing networks for prevention purposes informs behavioral decisions among individuals within the network.

- Secondary Prevention Principle: To prevent further transmission of HIV, those living with the virus must be made aware of their status and provided with sufficient resources to cope with the disease. 


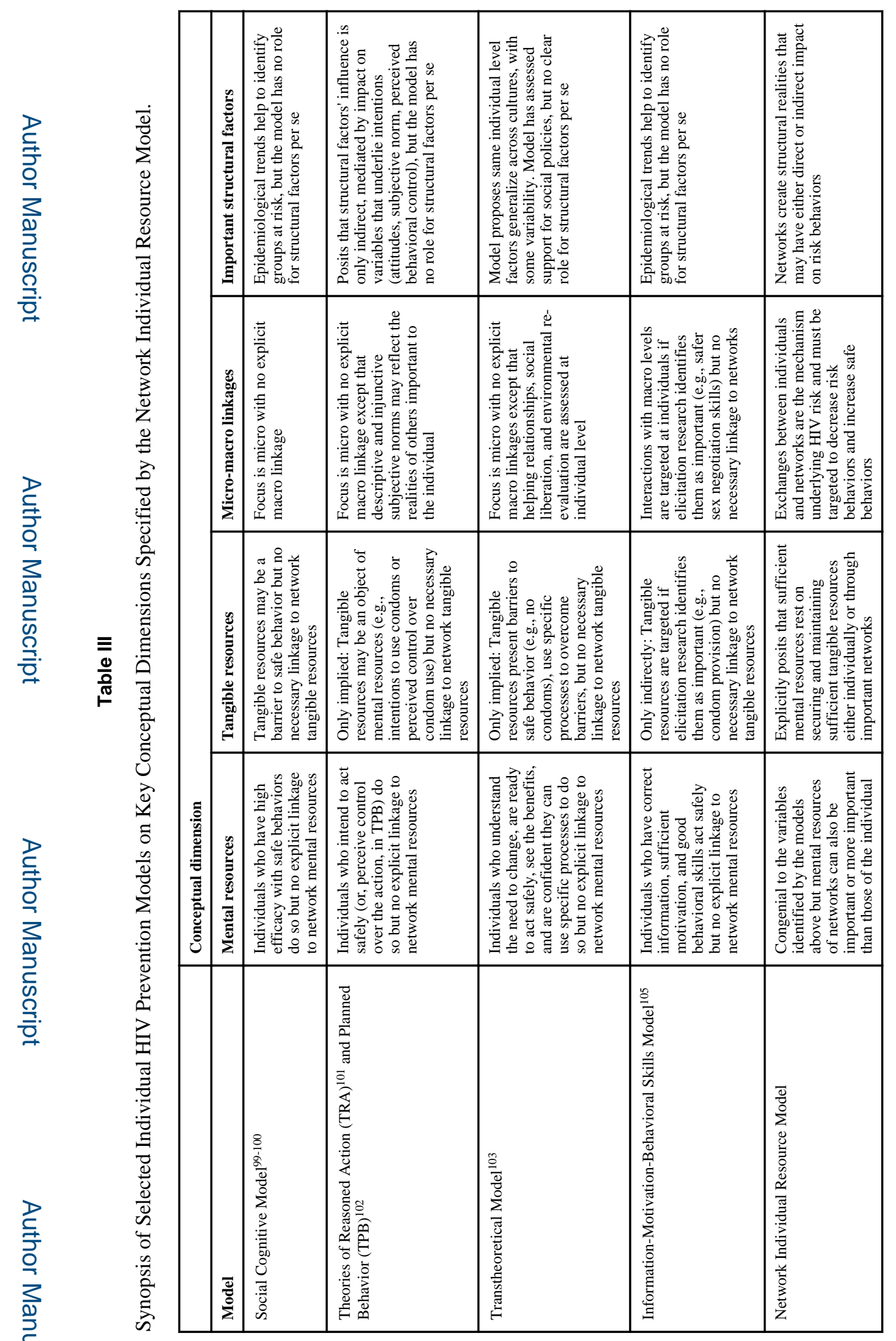

AIDS Behav. Author manuscript; available in PMC 2015 March 17. 